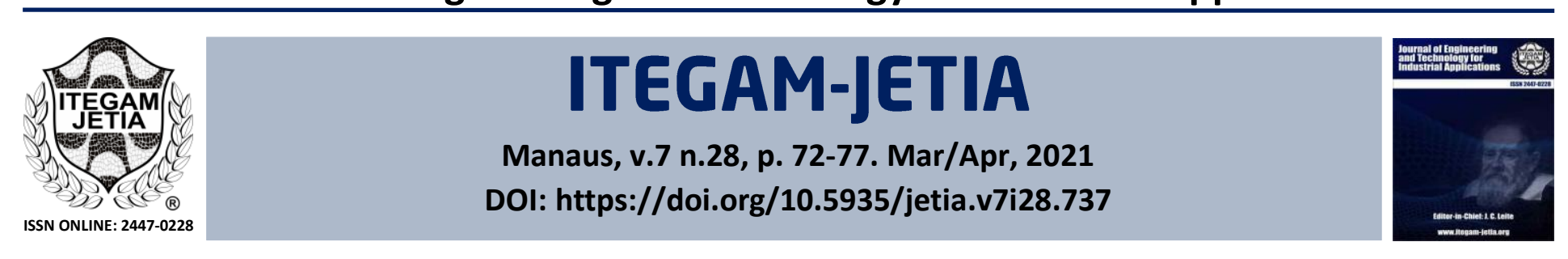

\title{
LONG-TERM SUSTAINABLE ENERGY PLAN TO REDUCE AIR POLLUTION IN THE REPUBLIC OF MOLDOVA
}

\author{
Erblin Shehu*1 \\ ${ }^{1}$ Central Directorate of the Health Operator (CDO), Ministry of Health, Tirana, Albania. \\ ${ }^{1}$ http://orcid.org/0000-0002-6249-8460 (i) \\ Email: *erblin.shehu@oshksh.gov.al
}

\begin{tabular}{ll}
\hline ARTICLE INFO & ABSTRACT \\
\cline { 2 - 2 } $\begin{array}{l}\text { Article History } \\
\text { Received: February } 02^{\text {th }}, 2021\end{array}$ & This paper is an energy system analysis of current energy systems in the Republic of \\
Accepted: April $01^{\text {th }}, 2021$ & Moldova. By recognizing the adverse health effects of pollution-based energy sources, a \\
Published: April $30^{\text {th }}, 2021$ & new energy plan for the Republic of Moldova is introduced. This sustainable energy plan is \\
& based on three main renewable energy sources: wind power, solar energy, and pumped \\
heywords: & hydropower. In addition, the amount of energy produced for electricity and heat, \\
Energy plan, & transportation and other residential, commercial, and industrial purposes is assessed and \\
Sustainable energy, & calculated. Then, based on the accessibility of these three main sustainable energy sources \\
Carbon footprint, & in Moldova, a feasible redistribution of the amount of energy accordingly is suggested. This \\
Pollution-based energy sources, & long-term energy plan would serve as a geo-political strategy that also provides Moldova \\
with the opportunity to reduce air pollution and increase their quality of life.
\end{tabular}

Moldova

Copyright (02016 by authors and Galileo Institute of Technology and Education of the Amazon (ITEGAM). This work is licensed under the Creative Commons Attribution International License (CC BY 4.0).

\section{INTRODUCTION}

Moldova is a small landlocked country in Eastern Europe located in between Romania and Ukraine. Although it is an independent country since 1991, it has always been under the political, economic, and sometimes military influence of countries like Russia and Ukraine [1][2]. The country's aspirations for the future are towards the west, joining the European Union and rising its economic level to a European standard. But they cannot do so, with the continuous influence of foreign regional superpowers, especially regarding the country's energy use.

Most of the country's energy production comes from natural gas and petroleum, both of which are sources imported by other countries in the region, mainly Russia and Ukraine [1][2]. Finding a way to make the Republic of Moldova produce its energy from its own resources, would be crucial and would make a huge impact in its geo-political position in the region. Fortunately, there are a lot of renewable sources of energy available in Moldova where the three most important ones include wind power, solar energy, and pumped hydropower [3]. Based on these sources of energy is possible to create a sustainable energy plan that would cover all the energy needs of the country. Through using the available renewable energy sources such as wind, solar energy and filling the gaps with hydropower and biomass energy, Moldova would be able to cut the import of natural gas and petroleum by more than half. This would result in a more stable and selfdependent economy, which would create more possibilities for Moldova to reduce air pollution and increase their quality of life.

\section{MATERIALS AND METHODS}

This paper is an energy system analysis of current energy systems in the Republic of Moldova. The main discourse of the paper revolves around the Energy Flow Charts created by the Lawrence Livermore National Laboratory in Canada for the Department of Energy's National Nuclear Security Administration. To calculate the amount of energy produced for residential, commercial, and industrial purposes, the energy Flow Chart of the Republic of Moldova was assessed. Then, a renewable energy plan for the year 2050 is introduced based on three main sustainable energy sources available in the region: wind power, solar energy and pumped hydropower.

To find out what energy sources were feasible for implementation, official governmental websites of the Republic of Moldova were reviewed. Energy data was collected from the Flow 
Charts of the Lawrence Livermore National Library and then calculated while taking into consideration wind power and solar energy sources. All the measurements and calculations were done in petajoule and in kilowatt-hour. In the end, while using the build a diagram tool: Sankey MATIC (BETA), a new flow chart for the Republic of Moldova was created portraying the renewable energy plan for the year of 2050 .

\section{RESULTS AND DISCUSSIONS}

\section{III.1 THE REGION}

According to Lawrence Livermore National Library, Moldova produced $138 \mathrm{PJ}$ in 2011 which is around $3.83 \times 1010$ $\mathrm{kWh}$. From this amount, there was $64 \mathrm{PJ}$ used for Electricity and Heating which is about $1.78 \times 1010 \mathrm{kWh}$ [4]. Most of the energy consumed in Moldova is used to produce electricity and heat for residential, commercial, industrial as well as a very small amount for transportation. In general, transportation in Moldova uses about $16 \mathrm{PJ}$ which is about $4.44 \mathrm{x} 109 \mathrm{kWh}$. This includes public transportation as well as individual cars. All this information is illustrated in figure 1 below. Relatively speaking, this energy is not a lot but almost most of this energy comes from petroleum, which is a source that Moldova doesn't have and needs to import it from other countries.

So far, most of Moldova's energy comes from the use of natural gas from that produces $94 \mathrm{PJ}$ which is about $2.61 \times 1010$ $\mathrm{kWh}$. Almost all of this energy is used to produce electricity and heating, as mentioned above, about 64 PJ. The rest is distributed in a way that $16 \mathrm{PJ}$ is used for industrial purposes in factories and production facilities, 4.6 PJ for commercial purposes in stores and supermarkets, and $13 \mathrm{PJ}$ used for residential purposes which could be mostly for cooking.

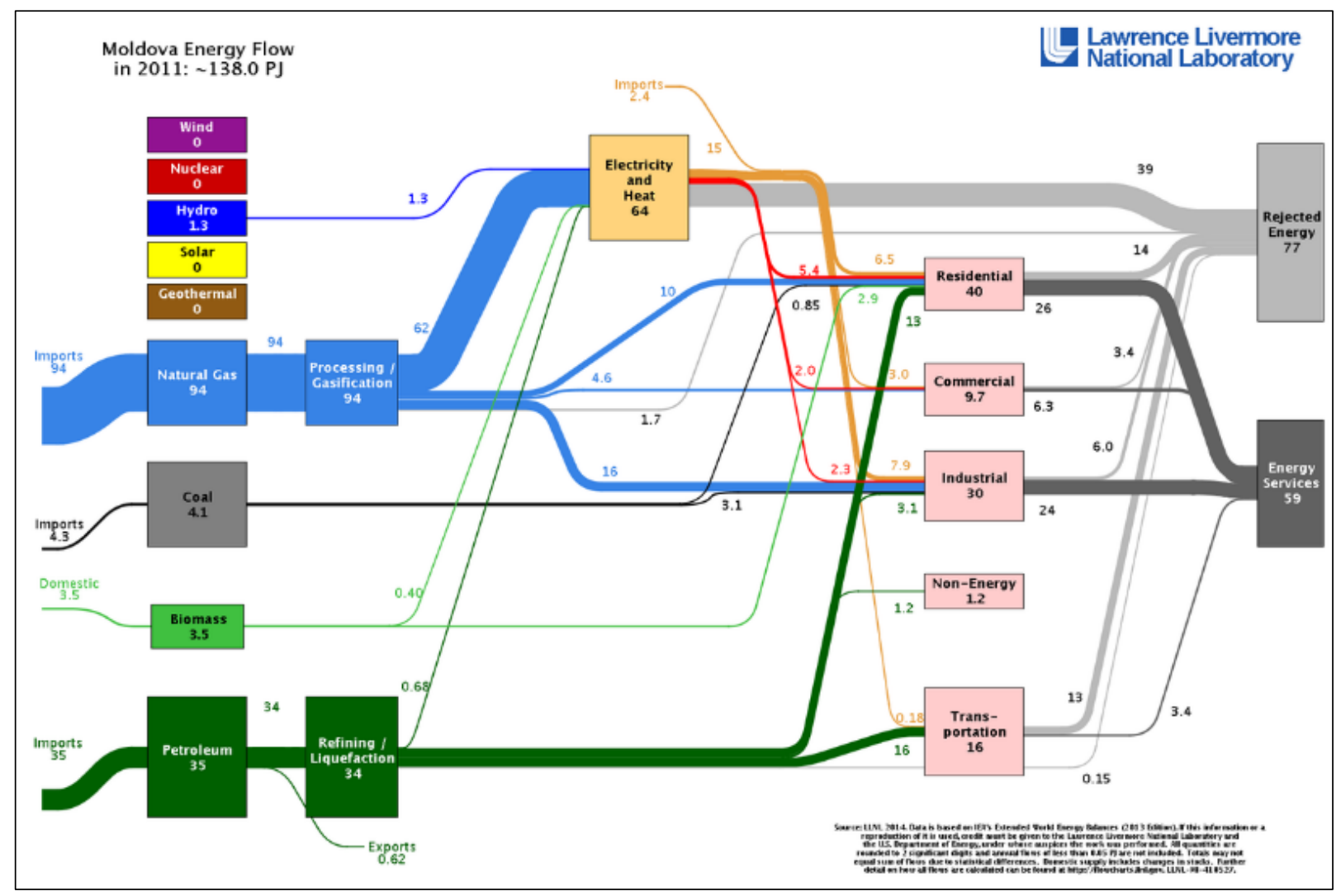

Figure 1: Moldova Energy Flow Diagram in 2011: 138.0 PJ.

Source: [4].

Since a considerable amount of the natural gas is used for residential purposes, it makes it a great way to save the environment because using natural gas for cooking has a lower carbon footprint that burning wood, which is a more traditional way used by households for heating and cooking, especially during winter days. However, the fact that most of the energy that comes from natural gas is used for producing heat and electricity its not very efficient, mainly because there are better and more efficient and available options for the Republic of Moldova. In addition, Moldova imports the whole amount of Natural Gas that is uses, so 94 PJ [5].

Right after natural gas, the second most used source of energy is petroleum that produces about $35 \mathrm{PJ}$, which is $9.72 \times 109$ $\mathrm{kWh}$. According to the existing literature the petroleum used by the Republic of Moldova is also imported by other countries. From 35 $\mathrm{PJ}$ of petroleum, $1 \mathrm{PJ}$ is used to refine and liquefy it. The $34 \mathrm{PJ}$ left, is distributed among residential use, industrial use, and most important transportation. It is seen that transportation in Moldova uses only 3 PJ more than what is being used for residential purposes. A very small amount of it also goes for heat and Electricity production.

Other sources of energy already being used in Moldova include coal (4.1 PJ) which is also imported, hydro (1.3 PJ) and Biomass (3.5 PJ). The latter two, are the only domestic sources of energy that Moldova uses. There are only 3 co-generation power plants in the whole country that produce both electricity and heat and only one hydro plant [3].

Implementing solar energy in Moldova, where there are about 240 sunny days in a year would supply all the country energy needs because it could produce about $4.3 \times 1013 \mathrm{kWh}$ which is much more than what the Republic of Moldova used in year 2011 [6]. Also. the wind power in many areas of Moldova reaches 5 to 6 
$\mathrm{m} / \mathrm{s}$, which means that in general we would be able to generate about $2 \mathrm{~W} / \mathrm{m}^{2}[6]$.

\section{III.2 THE PLAN}

By 2050 the republic of Moldova will be able to produce $140 \mathrm{PJ}$ which is $2 \mathrm{PJ}$ more than what it produced in 2011. If we would incorporate solar energy and wind power in the energy system by 2050 , Moldova will be able to cut its natural gas imports by almost 62 PJ. This amount corresponds to the amount being used to produce electricity and heat. In this case the energy plan illustrated in this paper suggests that the republic of Moldova will be able to produce all its electricity and heat from domestic renewable resources. Compered to its current use of petroleum, the plan doesn't change anything because petroleum, indeed is one of the most needed source of energy for vehicles and automobiles. For a developing country like Moldova will be very hard to replace all the cars, buses and airplanes that run on petroleum, with hybrid or electric automobiles. From the amount of petroleum imported in 2011 (35 PJ), 16 PJ was used for transportation and 13 PJ was used for residential purposes. By implementing this plan, the Republic of Moldova will be able to reduce the amount of petroleum produced by $18 \mathrm{PJ}$. Petroleum consumed in residential settings is mainly used for heating, and cooking [7]. By implementing this plan, the $18 \mathrm{PJ}$ that comes from petroleum will be able to come in the form of electricity and heat from renewable resources.

From 140 PJ energy that will be produced by 2050, the republic of Moldova will be able to stop using and importing coal. In 2011, 4.3 PJ was imported from countries such as Russia and Ukraine and 4.1 PJ was produced within the Republic of Moldova [1][2]. Almost $90 \%$ of the amount produced from coal was used in industrial settings and about $10 \%$ was used in residential settings. Although it might be difficult to substitute coal with other types of energy in industrial settings, it would be beneficial for business to eventually move away from these sources of energy and start using natural gas which is more environmentally friendly and relatively cheaper, as well as electricity, that after the implementation of this sustainable energy plan will come $100 \%$ from renewable resources.

There are three technologies that this energy plan includes, solar energy, wind power and the pumped hydropower energy. Moldova has a lot of potential to use solar energy for electricity production and that is why, among a lot of different technologies in the solar section, this plan encompasses the use photovoltaics solar panels. Moldova gets about 240 sunny days throughout a year period, which is pretty good for a North-Eastern European country. According to literature, Moldova sometimes is also called "the sunny land", and yet so far there is 0 PJ energy coming from this clean and renewable source of energy. From the global horizontal irradiation map created by GeoModel Solar and illustrated in Figure 2, its pretty clear to see parts of Moldova that get about 1400 $\mathrm{kWh} / \mathrm{m} 2$ annually [6]. This means that photovoltaics could produce about $3.83 \mathrm{kwh} /$ day $/ \mathrm{m} 2$ [8][9]. Although it is a small area that could produce this amount of energy, the rest of the south produces a similar amount that differs by $0.1 \mathrm{kwh} / \mathrm{day} / \mathrm{m} 2$ which is not that much of a difference. Installing photovoltaics in the South of Moldova energy would be able to be produced at about 32 PJ annually. Installing photovoltaics to produce this amount of energy would require an area of $6417 \mathrm{~km} 2$. (The $32 \mathrm{PJ}$ set to be produced by photovoltaics was divided with $3.83 \mathrm{kwh} /$ day which is the amount that some regions of Moldova can produce in $1 \mathrm{~m} 2$.) Photovoltaics could be installed either in the roofs of the houses and buildings in the south (although there are not many major cities), but most likely they could be installed in large fields.

There would be economic and technological challenges in storing this huge amount of energy that will be produced by implementing solar panels, so the most possible and feasible solution would be to use this energy throughout the day when the demand is high [10]. There might be issues with the solar energy considering weather patterns, and that is the reason why this plan suggests the implementation of wind power and pumped hydroelectric technologies that will fill in the gaps and will make sure that the supply meets the demand.

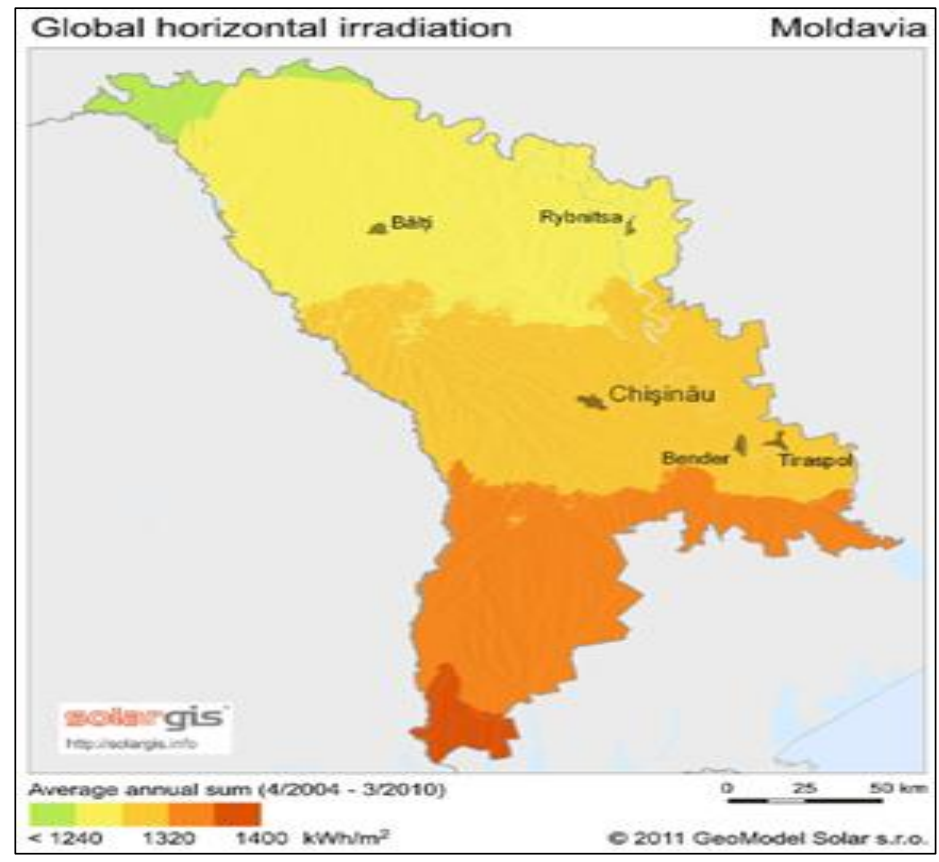

Figure 2: Horizontal Irradiation Map of Moldova.

Source: [6]

The republic of Moldova has a lot of potential to implement wind energy in its future sustainable energy plan. That is why the energy plan 2050 in this paper gives a lot of considerations to this technology. As you can see from this Wind Map by 3Tier in figure 
3, there are many areas in the Republic of Moldova where the wind speed reaches about 5-6 m/s [6]. Most of these areas are in the south, but there are a lot of other areas across the country where we can actually generate electricity from the wind speed. To generate electricity, we need at least $5 \mathrm{~m} / \mathrm{s}$ of wind speed, which Moldova has in addition to many areas where the wind speed goes even higher. According to this plan, the Republic of Moldova will be able to generate $20 \mathrm{PJ}$ of energy annually by the year 2050 . All this energy will go towards producing electricity and heat for residential, commercial, industrial as well as transportation purposes.

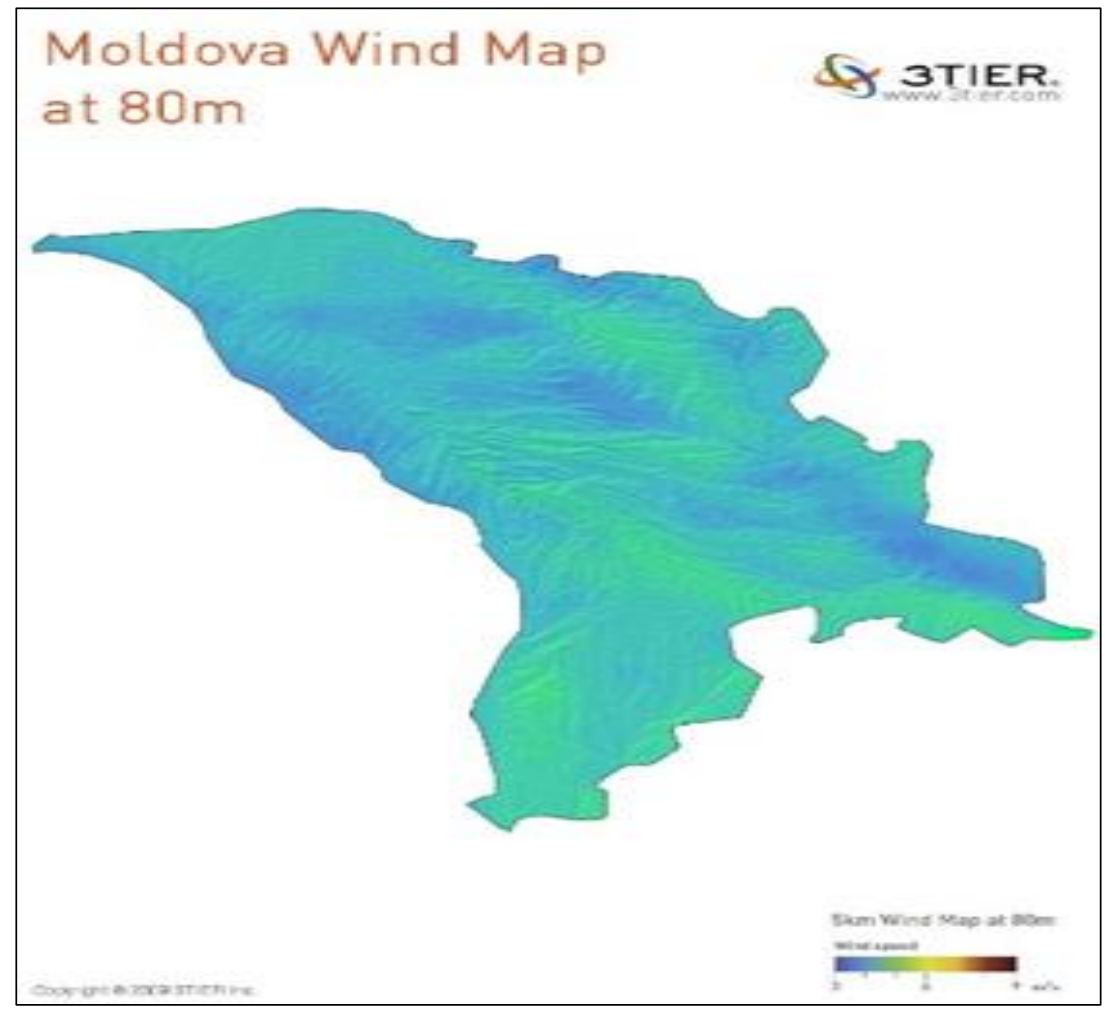

Figure 3: Wind Map of Moldova. Source: [6].

To generate this amount of energy we would need to build about 18802 windmills with $25 \mathrm{~m}$ diameter of blades, which might sound like a lot but the return on investment will be very high in the long run [8][11]. To find out how many windmills were needed the energy that could be produced by a windmill with 25 m blades could produce, which was $816 \mathrm{kwh} /$ day [8][11]. Then $20 \mathrm{PJ}$ was converted into $\mathrm{kwh} /$ day and dived by the amount that 1 windmill can produce. According to these calculations we would need an area of $11.8 \mathrm{~km} 2$, area which could easily be incorporated with the solar panels in the south and with the pumped hydropower facilities in the north. This number was found by firstly calculating how much area its needed for just one of them, which was $625 \mathrm{~m} 2$, and then through the necessary conversions this number was multiplied with the amount of windmills. The biggest challenge of this technology would be the amount of wind turbines that are needed, but if economies of scale are followed you could build bigger wind turbines that will reduce the number of them that need to be installed and in the same time will keep the energy the same.

The third technology that could be implemented is Pumped Hydropower. Calculations show that Moldova would be able to produce about $36 \mathrm{PJ}$ of energy and all of it could be used to produce electricity and heat. In order to produce this amount of energy, we would need about 380 3MW pumped hydropower facilities where each one of them would be about $2 \mathrm{~km} 2$. In order to find this number, $36 \mathrm{PJ}$ was divided with the amount of $\mathrm{kwh} /$ day that one $3 \mathrm{MW}$ pumped hydropower can produce [12].

As a result, implementing the pumped hydropower energy will require $760 \mathrm{~km} 2$ of area, and facilities would need to be built mostly in the north and the north east. This area was estimated by multiplying the amount of pumped hydropower facilities with the area that 1 of them. The drawback of using this technology is that more energy is needed to pump the water from the lower reservoir to the higher one, but that process could be done during the night when the demand for energy is low [12]. Also, these reservoirs could be used for raising fish for local consumption.

\section{III.3 ANALYSIS}

The implementation of this plan by 2050 comes with a considerable amount of cost, because firstly the Government of Moldova has to manage the construction of all these new technologies. Also, it has to do all the necessary construction to connect them to the existing grid. If the Republic of Moldova sees it as a necessity to upgrade or change the whole grid, then the cost will rise up. However, this plan does not suggest the creation of a new grid, but just simply connecting these three new technologies with one another, in a way so they can be used together in cases when the demand for energy is too high or too low. On the other side the pumped hydropower is a perfect storage technology that would help in cases when there is not enough supply of energy coming from both wind power and solar energy.

The U.S. Energy Information Administration has estimated some simple average of regional values for new generation of resources for plants entering service in 2022. In the absence of finding accurate information about the country of Moldova and the region of Eastern Europe, the US LCOEs were 
used as an approximate, even though the prices of incorporating these technologies would be lower in Moldova because there is cheaper labor available as well as less taxes and regulations.

Constructing and installing $6417 \mathrm{~km} 2$ of solar photovoltaics which will produce $36 \mathrm{PJ}$, will cost around \$756,500,000 USD [13]. To find that, this amount of energy was converted in MWh and then it was multiplied with the LCOE estimated by the U.S. Energy Information Administration. The same approach as to find how much it costs to construct and install the wind turbines and the pumped hydropower facilities was used. Calculations show that, constructing 18802 wind turbines with 25 m blade diameter will cost about $\$ 356,720,000$ USD. On the other side, constructing the 380 pumped hydropower facilities will cost about $\$ 662,000,000$ USD. So, to implement this energy plan in total would cost $\$ 1,775,220,000$ USD.

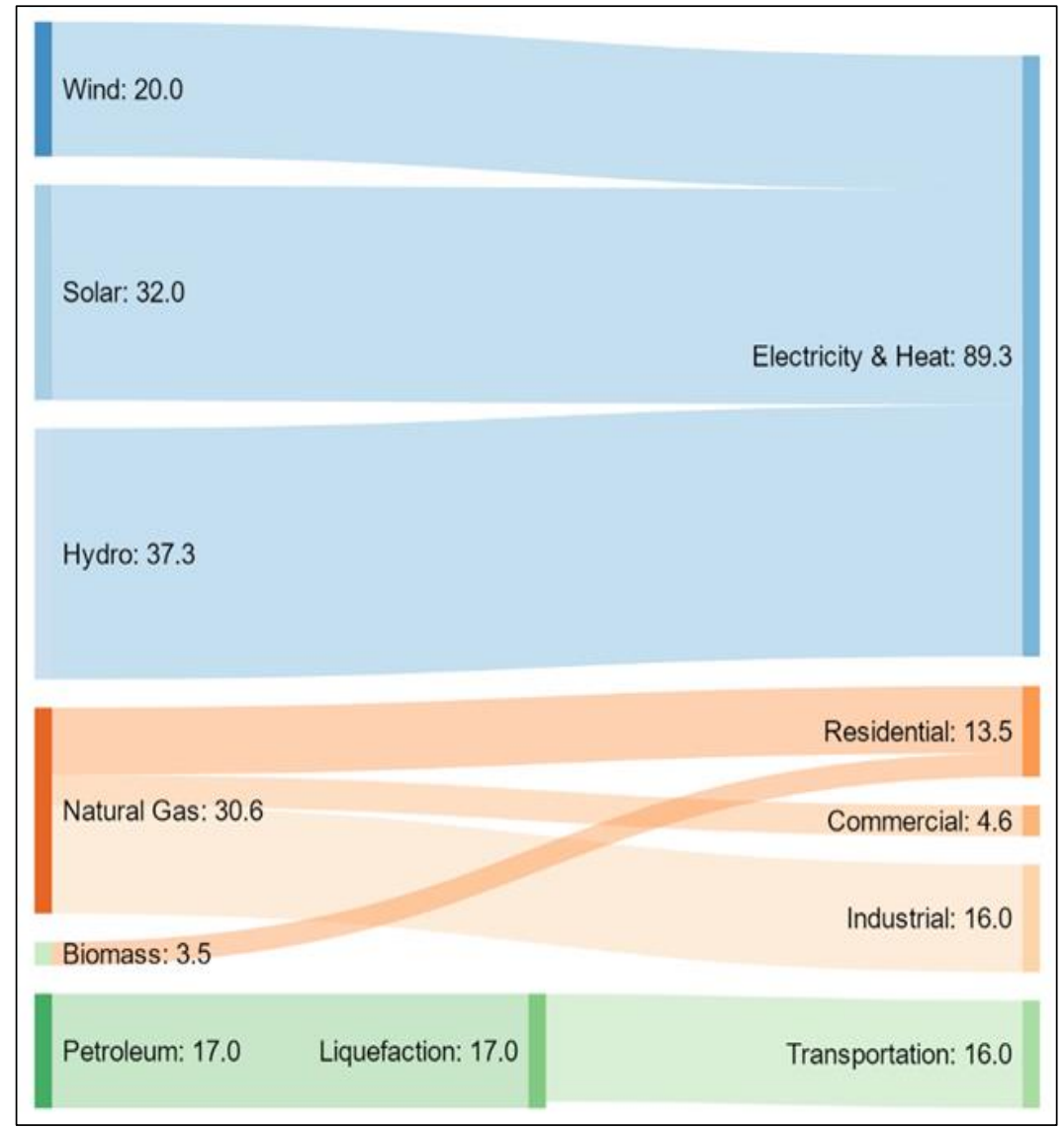

Figure 4: Moldova Energy Flow in 2050: 140.4 PJ.

Source: [14].

According to the Central Intelligence Agency (CIA), Moldova's GDP in 2016 was about $\$ 18.54$ billion USD [15] As calculated, this energy plan would cost about $\$ 1.8$ billion USD, amount which the Republic of Moldova has the full capacity to build and implement these new energy facilities. A lot of construction and maintenance jobs will be created, the buying power will rise and therefore the country will set the foundations of a stronger economy in the near future.

\section{CONCLUSIONS}

Based on the calculations done in this paper, it makes a lot of sense economically to implement this type of energy plan in the Republic of Moldova. The government has to spend only a small portion of its annual GDP to implement all three technologies that this energy plan is suggesting by also providing so many jobs for the Moldovans as well as other people in that region. According to the Central Intelligence Agency, the unemployment rate in 2016 was $6.3 \%$ [15]. Thanks to the creation of these new jobs the unemployment rate will drop considerably. Also, there will be less imports of natural gas and petroleum which will considerably affect the economy of the country as well as its geopolitical position in the region.
In addition, the implementation of a new sustainable energy plan makes sense environmentally because through constructing these new energy facilities and installing these new technologies the country of Moldova will be able to produce $100 \%$ of its electricity and heat from renewable resources. There will be a lot of $\mathrm{CO}_{2}$ emitted in the atmosphere during the time of construction of these facilities but considering the fact that these technologies emit $0 \mathrm{lbs}$. of $\mathrm{CO}_{2}$ in the atmosphere, it will pay off in the long run.

The implementation of this energy plan will make a lot of sense socially, because it will provide people the opportunity to get jobs. Most of the population is employed in agriculture and services, but with construction and installation of these new technologies there will be so many other jobs available, from which people will be able to earn more money, afford buying more things and therefore raise their standard of living.

\section{ACKNOWLEDGMENTS}

The author would like to acknowledge the Sustainable Energy course at Allegheny College as well as the book "Sustainable Energy - without the hot air" from David MacKay for the inspiration to write this scientific paper and for the technical 
guidance to conduct the necessary calculations throughout the paper.

\section{AUTHOR'S CONTRIBUTION}

Conceptualization: Erblin Shehu.

Methodology: Erblin Shehu.

Investigation: Erblin Shehu.

Discussion of results: Erblin Shehu.

Writing - Original Draft: Erblin Shehu.

Writing - Review and Editing: Erblin Shehu.

Resources: Erblin Shehu.

Supervision: Erblin Shehu.

Approval of the final text: Erblin Shehu.

\section{REFERENCES}

[1] Gelb, B. A. (2007, January). Russian Natural Gas: Regional Dependence. Library Of Congress Washington Dc Congressional Research Service.

[2] Yafimava, K. (2011). The transit dimension of EU energy security: Russian gas transit across Ukraine, Belarus, and Moldova. OUP Catalogue.

[3] Ministry of Environment and Natural Resources, 2009. Second National Communication of the Republic of Moldava Under the United Nations Framework Convention on Climate Change, 316 pp.

[4] Energy Flow Charts. Lawrence Livermore National Laboratory. (2011) Retrieved from: https://flowcharts.llnl.gov/commodities/energy.

[5] UNDP, 2009. Climate change in Moldova. Socio-economic impact and policy options for adaptation. National Human Development Report 2009/2010: 224 pp.

[6] Free Wind and Solar Resource Maps. Vaisala, www.vaisala.com/en/lp/freewind-and-solar-resource-maps.

[7] European Environment Agency (EEA), 2005. Vulnerability and adaptation to climate change in Europe. Technical report No 7/2005.

[8] MacKay, D. (2008). Sustainable Energy-without the hot air. UIT cambridge.

[9] Key, T. (2007). Solar photovoltaics: Expanding electric generation options. Electric Power Research Institute.

[10] Dennis, C. (2006). Solar Energy: Radiation Nation. Nature, 443(7107), 23-24.

[11] Halkema, J. A. (2006). Wind energy: Facts and fiction. Energy \& Environment, 17(4).

[12] Mandle, K. T. (1988). Dinorwig pumped-storage scheme. Power Engineering Journal, 2(5), 259-262.

[13] US Energy Information Association. (2017). Levelized Costs of New Generation Resources in the Annual Energy Outlook 2017. US Department of Energy.

[14] SankeyMATIC (BETA): Build a diagram. http://www.sankeymatic.com/build.

[15] The World Factbook: MOLDOVA. Central Intelligence Agency. Central Intelligence Agency, 12 Jan. 2017. 